Entrevista

\section{Conversando con el editor jefe de la British Dental Journal, Dr. Hancocks, por los 150 años de la revista}

Susana Maria Salazar Marocho 1,a

1 University of Mississippi Medical Center, School of Dentistry, Department of Biomedical Materials Science, Mississippi, EEUU.

a Ph.D. en Odontología Restauradora y post-doctora en Biomedical Materials Science.

\section{Correspondencia:}

Susana Maria Salazar Marocho: ssalazarmarocho@umc. edu

University of Mississippi Medical Center - 2500 North State Street, Room D528-6B, Jackson, MS 39216-4505 ORCID: 0000-0002-5366-7496

\section{In conversation with the Editor-in-Chief of the British Dental Journal, Dr. Hancocks, for 150 years of the journal}

Conflicto de intereses: ninguno.

Fuente de financiamiento: autofinanciado.

Recibido: 01/12/21

Aceptado: 06/12/21

Publicado: 21/01/22

\title{
Resumen
}

La British Dental Journal celebrará en el 2022 su $150^{\circ}$ aniversario. Su editor jefe, Dr. Hancocks, tiene el liderazgo de esta revista por más de 15 años. En el encuentro con él por videconferencia, nos relata los logros, pilares, y desafíos que esta revista tuvo a lo largo de los últimos ańos para crecer y alcanzar su longevidad y éxito. El Dr. Hancocks también comparte su rol y manejo de responsabilidades en su rol de líder de la revista y su trabajo conjunto con la British Dental Association.

Palabras clave: Videoconferencia; Entrevista; Odontología; Revistas electrónicas (fuente: DeCS BIREME).

\begin{abstract}
The British Dental Journal will celebrate its $150^{\text {th }}$ anniversary in 2022. Its editor-in-chief, Dr. Hancock, has led this journal for more than 15 years. In the meeting with him by videoconference, he tells us about the achievements, pillars, and challenges that the journal had over the last years to grow and achieve its longevity and success. Dr. Hancock also shares his role and handling of responsibilities in his role as leader of the journal and his joint work with the British Dental Association.
\end{abstract}

Keywords: Videoconference; Interview; Dentistry, Electronic journals (source: $\mathrm{MeSH}$ NLM). 


\section{Introducción}

La renombrada revista científica "British Dental Journal" cumplirá 150 años en abril del 2022. Este notable hito se alcanza con el liderazgo del Dr. Stephen Hancocks como editor jefe, quien ha estado en este cargo desde el 2004. Dr. Hancocks es graduado en odontología de la "University College Hospital Dental School", además de ser miembro honorario de prestigiosas asociaciones odontológicas: British Dental Association y American Dental Association, y ser citado en la lista de honor de la Federación Dental Internacional (FDI).

En un encuentro especial vía videoconferencia, el Dr. Hancocks (Figura) nos cuenta detalles de la revista, de su historia, y de su recorrido como editor jefe.

\section{Entrevista}

Dr. Hancocks ¿Cuáles cree que han sido los logros más importantes de la revista a lo largo de este tiempo?

Definitivamente nuestros 150 años. Es bastante extraordinario pensar en la historia y el camino recorrido por nuestra revista desde 1872. Estamos emocionados y listos para festejar este gran día. Hasta ahora tenemos planeada una celebración en persona en junio o julio con los miembros de la British Dental Association, comité editorial y colaboradores directos. Esperemos que las condiciones de la pandemia no cambie nuestros planes. Tendremos una edición especial de la revista en la cual republicaremos los 12 artículos de mayor impacto y portadas que han sido publicadas por nuestra revista.

¿Qué pilares considera que contribuyeron a esos logros?

Nuestros pilares, sin duda alguna, son la confianza e integridad que hemos construido a lo largo de los años. Gracias a eso hemos desarrollado y abordado temas relevantes del día a día de los clínicos, inclusive anticipándonos a los potenciales intereses de los lectores. Un gran giro transformador para nosotros, producto de estos pilares, fue convertirnos en una revista de acceso abierto. No puedo dejar de mencionar además la contribución de la solidez de la investigación que publicamos, el sistema de revisión por pares y el canal de debate que hemos creado para la profesión.

¿Cómo ha afectado la pandemia de COVID-19 a la investigación y publicación científicas?

Nos trajo más publicaciones. El número de artículos así como de escritores se elevó exponencialmente. Hemos estado muy ocupados en la parte de revisión de artículos.

¿Cuáles han sido los desafíos más difíciles que la revista ha experimentado y superado?

Creo que, personalmente, el desafío más difícil es encontrar un tema para el editorial dos veces al mes, a pesar de no parecer mucho, es un trabajo arduo. Tiene que tener 832 palabras y realmente tiene que ser muy preciso. Creo que en general, para el portafolio de nuestra

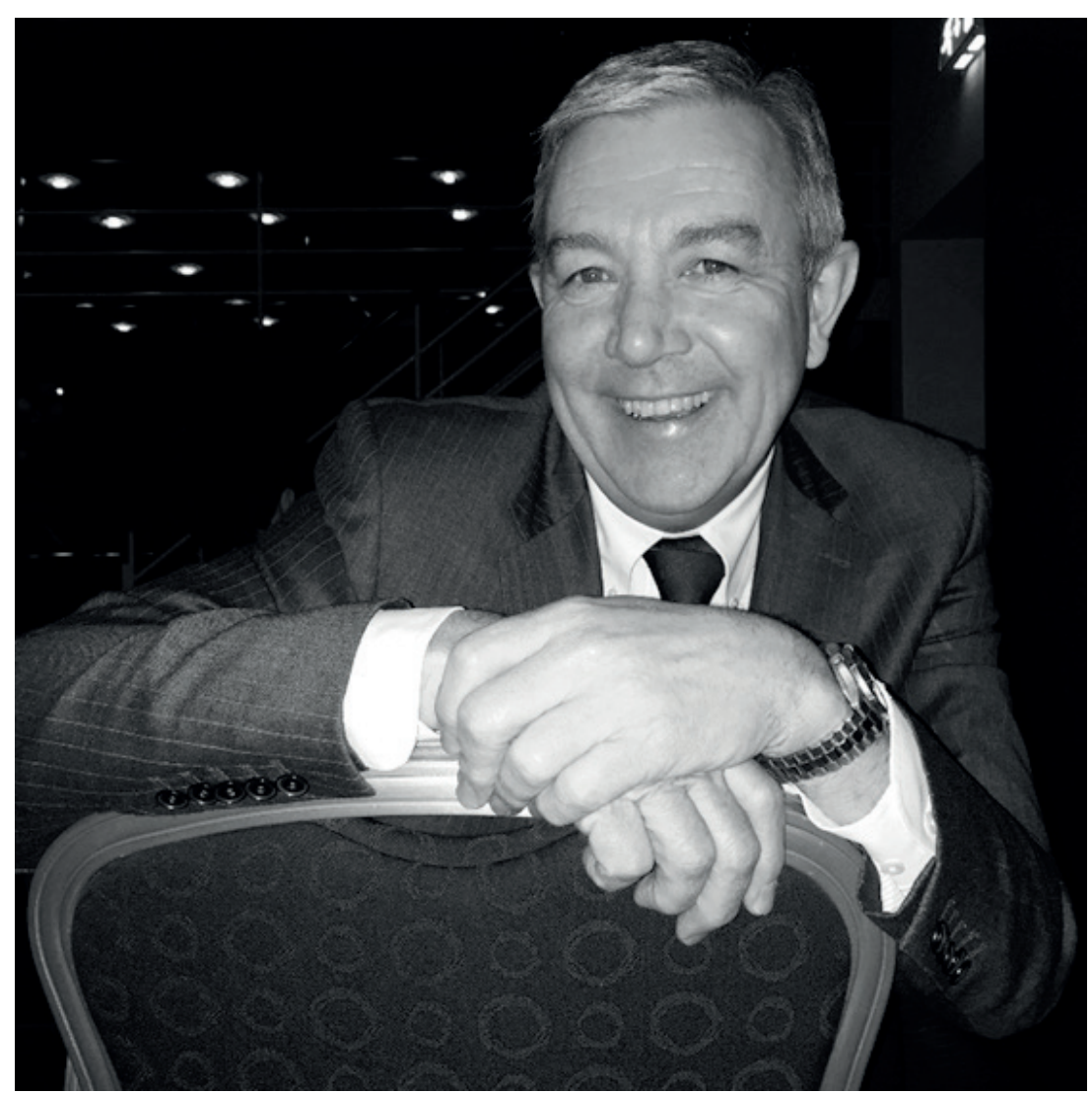

Figura. Dr. Hancocks, editor jefe de la Bristish Dental Journal 
revista, los desafíos se presentan conforme el mundo va evolucionando. Estos desafíos radican en la naturaleza ética de las investigaciones, desafíos en inclusión y diversidad, en plagio, y desafíos que resultan de la presión por publicar, incluyendo presiones financieras. En los últimos 5 años hemos tenido muchos desafíos que nos llevaron a poner más pautas y más cuidado con nuestra atención a los detalles de los artículos que recibimos y también en cómo editamos en el mes lo que publicamos.

De todos los aspectos que menciona, el de equidad y diversidad llamó mi atención ¿Cómo se implementa equidad y diversidad en una revista"?

Muy buena pregunta. Hemos conversado de esto con el equipo editorial muchísimas veces. Hemos abierto el abanico de publicaciones que aceptamos. Recientemente, hemos decidido mostrar interés en publicar artículos, por ejemplo, de diversidad racial en facultades de odontología principalmente en el Reino Unido, el balance de sexo femenino y masculino participantes en la vida académica, y en eventos odontológicos. Hemos intentado ampliar el debate en esos aspectos dentro de odontología, pero debo decir que no hemos tenido una respuesta masiva de los lectores hacia estos artículos, a pesar de que son temas provocadores y fuertes. Quizás las personas aún esten formando su opinión acerca de esos tópicos. Estamos intentando tener un mejor balance de esos temas en nuestra revista. Estoy muy agradecido con la British Dental Association, fundadores del British Dental Journal, por abrazar mis iniciativas y dar luz verde a las decisiones o giros que se han dado en la revista.

¿Puede contarnos sobre su trayectoria como editor jefe? ¿Cómo gestiona sus tareas diarias?

El Dr. Hancocks es el decimoquinto editor jefe de dicha revista, y su respuesta a esta pregunta fue la siguiente: Es casi hacer malabares con todas las tareas inmediatas. Publicamos dos números por mes, y eso nos hace la revista odontológica que más frecuentemente publica en el mundo. Esto claro trae implicaciones como revisión, producción, y juntar las diferentes partes de la revista. Soy increiblemente afortunado de contar con un equipo que ha permanecido constante en los últimos 10 años. Creo que eso dice todo. Tiene mucho valor que confiemos en nuestro trabajo en diferentes formas, casi podemos adivinar nuestros pensamientos y lo que vamos a decir. Los revisores también enriquecen a nuestra revista y a mi trabajo con su tremenda colaboración.

Como redactor jefe también respondo correos, cartas al editor, y además también siento la responsabilidad de motivar a los nuevos escritores. Es más, los jovenes dentistas son los que últimamente han contribuido más a nuestra profesión científicamente. Nuestro futuro está en sus manos.

\section{¿Qué opinión tiene de la investigación oral que se realiza} en América Latina?

No tengo a la mano los números exactos de la contribución de cada lugar del mundo, pero sí puedo decirte que la mayor cantidad de artículos enviados a nuestra revista son del Reino Unido, lo cual probablemente no es sorprendente. También recibimos muchos artículos de Europa, China y Japón. Actualmente venimos recibiendo artículos del sureste de Asia, algunos de Norteamérica y muchos de Sudamérica, más específicamente de Brasil, en el área de materiales dentales. Mi opinión en relación a la investigación en Sudamérica, es que son fuertes en materiales dentales.

BDJ open access journal comenzó 5 años atrás, y surgió por dos razones. Una de ellas es que queríamos abrir oportunidades para publicar artículos en asuntos más específicos, de un área determinada. Solía pensar que nuestro público objetivo eran lo dentistas y especialistas del Reino Unido, hasta que una vez un dentista de Egipto se acercó a mí mientras estaba en el cubículo de la revista en una reunión del International Association of Dental Research (IADR), y me dijo que él y sus colegas nos leian constantemente. Desde ese día, siempre que puedo menciono esto, y además agradezco ese comentario porque no veia el real alcance que tenia nuestra revista. Esperamos que este año hayamos publicado un número suficiente de artículos para comenzar el proceso de obtener un factor de impacto. Esto será un paso importante en nuestro avance.

\section{¿Qué sugerencias ofrecería a una revista cientifica dental joven? ¿Qué errores no cometer?}

Creo que probablemente algunas de las pistas sobre el camino que debe recorrer una revista joven se encuentran en algunas de las cosas que ya he mencionado, como tener un buen equipo, construir confianza, ser cortés y educado a pesar de los desacuerdos. Este último aspecto es una característica que una revista debe cultivar particularmente en el área científica. Los investigadores se casan con sus investigaciones, y son sensibles a críticas así como nosotros lo somos. Una revista joven debe gestionar todo el proceso de crítica y debate; por ejemplo, personalmente yo escribo una carta de agradecimiento a mis revisores y les dejo saber nuestra decisión de seguir con el artículo que revisó, a pesar que el sistema automatizado en línea lo hace por sí solo, igual me tomo el tiempo de escribir personalmente al revisor. Hace unos años, estaba tan ocupado que dejé de hacerlo, y unos meses después, algunos revisores me dijeron que era un acto muy cortés que ninguna otra revista tenía. Para mí es un acto de cortesía común. Es triste descubrir que nadie más lo hace. Realmente la revista no hubiera podido avanzar ni desarrollarse sin revisores, que son colaboradores voluntarios que brindan su tiempo.

Para una revista joven es importante construir relaciones con escritores, los futuros potenciales escritores, investigadores, autores, e instituciones.

Ha sido un honor este encuentro virtual para conversar y conocer más del Dr. Hancocks y de la British Dental Journal. ¡Feliz 150 aniversario a la British Dental Journal y a todos los autores, revisores, comité editorial y administrativos que a lo largo de los años han contribuido a su exitosa trayectoria! 